\title{
Impact of the implantation of a new curriculum in the process of learning in a Faculty of Dentistry in Brazil
}

\section{Roger Junges ${ }^{(a)}$ \\ Ruggiero Silveira Stello(a) \\ Fernando Freitas Portella ${ }^{(b)}$ \\ Cassiano Kuchenbecker Rösing ${ }^{(c)}$ \\ Susana Maria Werner Samuel(b)}
(a) School of Dentistry, Universidade Federal do Rio Grande do Sul, Porto Alegre, RS, Brazil.

(b) Laboratory of Dental Materials, School of Dentistry, Universidade Federal do Rio Grande do Sul, Porto Alegre, RS, Brazil.

(c) Department of Periodontics, School of Dentistry, Universidade Federal do Rio Grande do Sul, Porto Alegre, RS, Brazil.

Declaration of Interests: The authors certify that they have no commercial or associative interest that represents a conflict of interest in connection with the manuscript.

\section{Corresponding author:}

Cassiano Kuchenbecker Rösing

E-mail: ckrosing@hotmail.com

Received for publication on Jun 16, 2011 Accepted for publication on Sep 16, 2011

\begin{abstract}
The aim of the present study was to evaluate two dental curricula at a school of dentistry in southern Brazil. The study population included dentists trained in the last two classes of the institution's old curriculum ( $\mathrm{n}=98)$ and graduates of the first two classes of the new curriculum $(\mathrm{n}=56)$. A questionnaire with open and closed questions was used for an overall evaluation of different aspects of the curricula, such as study methods, importance given to basic sciences, quality of theoretical and clinical guidance, perception about skills needed to perform different dental procedures, professional goals and an overall assessment. Students in the new curriculum reported more frequent use of the internet $(69.6 \%)$ and scientific articles (50.0\%). More importance was given to the basic sciences in the new curriculum. Graduates of the old curriculum alleged themselves to be more capable of both performing conventional (99\%) and complex amalgam restorations (68.4\%), as well as three-unit fixed prostheses (62.2\%). Graduates of the new curriculum alleged higher capability with periodontal surgeries (48.2\%), treatment of temporomandibular joint (TMJ) disorders (58.1\%) and public health planning (78.6\%). Regarding professional goals, the new curriculum was associated with an increase in the graduates' willingness to work in the public health system and to pursue an academic career. New curriculum graduates reported higher overall assessments regarding their educational, as well as theoretical and clinical, outcomes. A new curricular approach was associated with several changes from the perspective of the students.
\end{abstract}

Descriptors: Education, Dental; Education, Continuing; Educational Measurement; Curriculum; Health Education.

\section{Introduction}

Dental curricula in various universities around the world have undergone several modifications throughout the years. These changes have been based on efforts to achieve better outcomes in dental education, changes in the prevalence and severity of oral diseases, and improvements regarding treatment expectations among the general public. ${ }^{1}$ Thus, evaluating the performance of a dental curriculum involves continuous updates to the educational process. Expectations and satisfaction with dental curricula have already been reported from several institutions..$^{1-4}$ Historically, dentistry was established as a branch of medicine, although 
it has become an independent profession in most countries. In recent years, the tendency has been to include more generalized medical subject matter in the dental school curriculum. ${ }^{3}$ The so-called old curriculum established by the School of Dentistry of the Federal University of Rio Grande do Sul, in southern Brazil, lasted twenty years (ending in 2005) and was based on a very traditional view of didactics. Clinical teaching was generally fragmented in discipline-oriented clinics, where students treated patients for specific problems related to only that particular specialty.

The national Law for Curricular Guidelines in Dental Schools ${ }^{5}$ - approved in 2001 in Brazil stated that the new dental professional must have a generalist, critical, humanist and reflective formation, which allows him/her to work in different levels of the health care system based on technical accuracy and scientific evidence. Considering these principles, the new curriculum of the School of Dentistry of the Federal University of Rio Grande do Sul was developed. The traditional teacher-dominated, lecture-based teaching format was substituted by a mutual, bi-directional learning process. The main alterations in the curriculum were linked to the exclusion of traditional specialty disciplines, with clinical teaching undergoing significant integration. Additionally, "Integrative Seminars" were created to promote aggregation of the basic sciences and professional training. Also, emphasis was placed on dental public health, with ample dedication to supervised practice in community dentistry settings. Satisfaction rates among students have been used to measure acceptance of a new curriculum. ${ }^{3,6}$

The aim of this study was to compare two curriculum models for undergraduate dental education in the Federal University of Rio Grande do Sul, one of them no longer active and another that was established to replace the former, as of expectations and perceptions of the students.

\section{Methodology}

The study population included dentists trained in the final two classes with the old curriculum ( $\mathrm{n}=98$ from a total of 102) and graduates of the first two classes with the new curriculum $(\mathrm{n}=56$ from a total of 59). The response rate of the study was $95.65 \%$. This study was approved by the Ethics Committee of the School of Dentistry of the Federal University of Rio Grande do Sul. All participants signed an informed consent form.

A questionnaire with both open and closed questions was used for an overall evaluation of the different aspects of the two different curricula. Participants answered the questions at the end of their last semester of dental training. One of the authors of the study conducted data collection, by means of applying the questionnaire, giving opportunity for clearing any possible doubt. The questionnaire was based on instruments used in two previous studies, ${ }^{1,7}$ which made a similar comparison between different curricula in a group of universities. The participants were asked if they felt capable of performing a series of dental procedures listed on the questionnaire, as well as to qualify their clinical and theoretical guidance on a five-level scale ranging from poor to excellent. In addition, students from both curricula rated their overall academic educational experience on a visual analogue scale (VAS) ranging from one to ten. The frequency of one's personal study methods was also one of the topics. The importance of basic sciences was addressed on a scale from one (worst) to five (best). Students' professional goals were also analyzed. The questionnaire was previously tested for proper comprehension of the questions and was based on focal group discussions. To avoid biases regarding any of the curricula under evaluation, the questions were conceived based on matters related to general dentistry education, and individual numeric evaluations were included to effectively assess levels of satisfaction. A trained researcher applied the questionnaires for a group of non-participants, which showed no major issues. Therefore, the instrument was considered understandable.

Data were collected and analyzed using descriptive statistics as relative frequency of answers for the selected questions. In some cases, groups of answers were merged to facilitate interpretation. Considering the perceived ability to perform different dental procedures, the two curricula were compared by chi-square or Fisher's exact test as applicable. The adopted significance level was $5 \%$. 


\section{Results}

The reported study methods showed that students from the two curricula under evaluation had considerably different habits (Table 1). Book consultations remained similar in both curricula, however library use was lower in the new curriculum. Internet usage increased from $41.8 \%$ to $69.6 \%$. The use of scientific articles often as an instrument of study changed from $10.2 \%$ in the old curriculum to $50 \%$ in the current one.

Students who graduated under the new curriculum gave higher ratings to the importance of basic sciences as a whole (Table 2). While $84 \%$ of the students rated general microbiology with a grade of 4 or 5 regarding its importance in the new curriculum, only $58.2 \%$ rated it as high in the old curriculum. The same pattern was observed regarding general histology and biochemistry. Ratings of 5 for general anatomy were significantly higher among participants of the new curriculum.

Theoretical assessment was rated higher by students who graduated with the new curriculum (Figure 1). The quality of clinical guidance was also

Table 1 - Study methods utilized by the students.

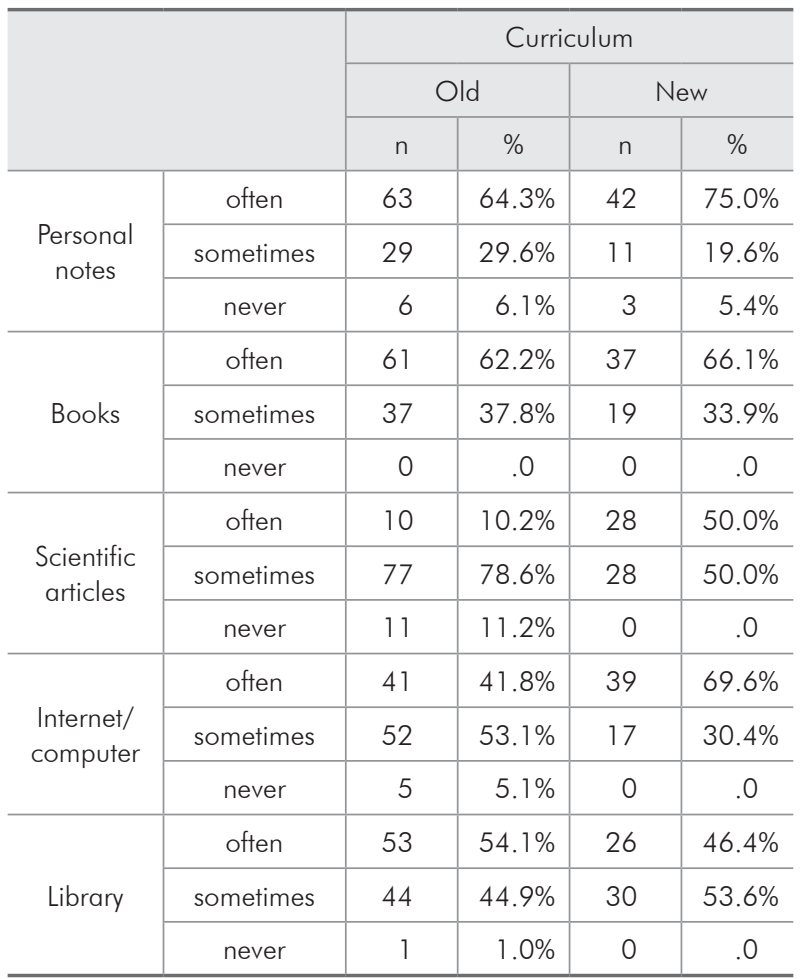

rated higher by students from the new curriculum (Figure 2), with nearly $11 \%$ reporting "excellent" compared to roughly half as many from the old curriculum.

Table 3 shows the responses for the supposed ability of graduates in performing particular clinical procedures. Students who graduated with the old curriculum alleged themselves to be more capable of performing conventional and complex amalgam restorations, as well as three-unit fixed prostheses. Among graduates of the new curriculum, responses

Table 2 - Importance of basic sciences on a scale from 1 (worst) to 5 (best) reported by the students.

\begin{tabular}{|c|c|c|c|c|c|}
\hline & & \multicolumn{4}{|c|}{ Curriculum } \\
\hline & & \multicolumn{2}{|c|}{ Old } & \multicolumn{2}{|c|}{ New } \\
\hline & & $\mathrm{n}$ & $\%$ & $\mathrm{n}$ & $\%$ \\
\hline \multirow{5}{*}{ Microbiology } & 5 & 28 & $28.6 \%$ & 23 & $41.1 \%$ \\
\hline & 4 & 29 & $29.6 \%$ & 24 & $42.9 \%$ \\
\hline & 3 & 29 & $29.6 \%$ & 6 & $10.7 \%$ \\
\hline & 2 & 10 & $10.2 \%$ & 2 & $3.6 \%$ \\
\hline & 1 & 2 & $2.0 \%$ & 1 & $1.8 \%$ \\
\hline \multirow{5}{*}{ Anatomy } & 5 & 57 & $58.2 \%$ & 41 & $73.2 \%$ \\
\hline & 4 & 27 & $27.6 \%$ & 11 & $19.6 \%$ \\
\hline & 3 & 12 & $12.2 \%$ & 3 & $5.4 \%$ \\
\hline & 2 & 2 & $2.0 \%$ & 1 & $1.8 \%$ \\
\hline & 1 & 0 & .0 & 0 & .0 \\
\hline \multirow{5}{*}{ Histology } & 5 & 46 & $46.9 \%$ & 34 & $60.7 \%$ \\
\hline & 4 & 26 & $26.5 \%$ & 13 & $23.2 \%$ \\
\hline & 3 & 22 & $22.4 \%$ & 7 & $12.5 \%$ \\
\hline & 2 & 4 & $4.1 \%$ & 2 & $3.6 \%$ \\
\hline & 1 & 0 & .0 & 0 & .0 \\
\hline \multirow{5}{*}{ Biochemistry } & 5 & 28 & $28.6 \%$ & 19 & $33.9 \%$ \\
\hline & 4 & 28 & $28.6 \%$ & 22 & $39.3 \%$ \\
\hline & 3 & 29 & $29.6 \%$ & 10 & $17.9 \%$ \\
\hline & 2 & 11 & $11.2 \%$ & 3 & $5.4 \%$ \\
\hline & 1 & 2 & $2.0 \%$ & 2 & $3.6 \%$ \\
\hline \multirow{5}{*}{ Pathology } & 5 & 71 & $72.4 \%$ & 44 & $78.6 \%$ \\
\hline & 4 & 17 & $17.3 \%$ & 10 & $17.9 \%$ \\
\hline & 3 & 10 & $10.2 \%$ & 1 & $1.8 \%$ \\
\hline & 2 & 0 & .0 & 1 & $1.8 \%$ \\
\hline & 1 & 0 & .0 & 0 & .0 \\
\hline
\end{tabular}


Table 3 - Self-reported ability to perform specific dental procedures between graduates of the two curricula.

\begin{tabular}{|c|c|c|c|c|c|}
\hline \multirow{2}{*}{ Procedure } & \multicolumn{2}{|c|}{ Old curriculum } & \multicolumn{2}{|c|}{ New Curriculum } & \multirow{2}{*}{$\mathrm{p}$} \\
\hline & $n$ & $\%$ & $n$ & $\%$ & \\
\hline Supragingival scaling & 98 & 100.0 & 56 & 100.0 & - \\
\hline Subgingival scaling & 98 & 100.0 & 56 & 100.0 & - \\
\hline Periodontal surgery & 14 & 14.3 & 27 & 48.2 & $0.000^{*}$ \\
\hline Complex amalgam restoration & 67 & 68.4 & 10 & 17.9 & $0.000^{*}$ \\
\hline Conventional amalgam restoration & 97 & 99.0 & 46 & 82.1 & $0.000^{*}$ \\
\hline Complex composite restoration & 86 & 87.8 & 54 & 96.4 & $0.072^{*}$ \\
\hline Conventional composite restoration & 98 & 100.0 & 55 & 98.2 & $0.184^{*}$ \\
\hline Full denture & 62 & 63.3 & 39 & 69.6 & $0.423^{*}$ \\
\hline Removable partial denture & 87 & 88.8 & 48 & 85.7 & $0.578^{*}$ \\
\hline Fixed crowns & 94 & 95.9 & 52 & 92.9 & $0.410^{*}$ \\
\hline Three-unit fixed prostheses & 61 & 62.2 & 23 & 41.1 & $0.011^{*}$ \\
\hline Bigger bridges & 15 & 15.3 & 8 & 14.3 & $0.864^{*}$ \\
\hline Endodontic treatment in single-rooted teeth & 97 & 99.0 & 56 & 100.0 & $0.448^{*}$ \\
\hline Endodontic treatment in multi-rooted teeth & 76 & 77.6 & 49 & 87.5 & $0.129^{*}$ \\
\hline Simple orthodontics & 66 & 67.3 & 30 & 53.6 & $0.090^{*}$ \\
\hline Complex orthodontics & 0 & 0 & 0 & 0 & - \\
\hline Implant placement & 0 & 0 & 2 & 3.6 & $0.131^{* *}$ \\
\hline Implant maintenance & 11 & 11.2 & 11 & 19.6 & $0.151^{*}$ \\
\hline Treatment of deciduous teeth & 96 & 98.0 & 54 & 96.4 & $0.622^{* *}$ \\
\hline Treatment of the elderly & 93 & 94.9 & 54 & 96.4 & $1.000^{* *}$ \\
\hline Minor oral surgery & 76 & 77.6 & 49 & 87.5 & $0.129^{*}$ \\
\hline Treatment of TMJ disorders & 20 & 20.4 & 29 & 51.8 & $0.000^{*}$ \\
\hline Diagnosis of oral lesions & 83 & 84.7 & 53 & 94.6 & $0.065^{*}$ \\
\hline $\begin{array}{l}\text { Planning and execution of a community } \\
\text { dentistry program }\end{array}$ & 59 & 60.2 & 44 & 78.6 & $0.020^{*}$ \\
\hline
\end{tabular}

${ }^{*}$ chi-square; ${ }^{* *}$ Fisher's exact test.

pointed to an increase in their perceived ability to perform periodontal surgeries, provide treatment for TMJ disorders and perform duties in the realm of public health.

When asked about their future professional goals (Figure 3), 28.6\% of the old curriculum graduates reported that they intended to work exclusively in a private clinic while only $1 \%$ wanted to work strictly in the public system. Nearly half, or $45.9 \%$, reported a willingness to work in both systems. In contrast, only $12.5 \%$ of the students from the new curriculum expressed a desire to work exclusively in a private clinic while $8.9 \%$ wanted to work only in the public system. Similar to the rate expressed by old curriculum graduates, $44.6 \%$ of the new curriculum graduates stated that they would work in both systems. New curriculum graduates were also more interested in pursuing a future academic career, in a comparison with students from the old curriculum.

Figure 4 shows that new curriculum students provided higher ratings regarding their education in general. Nearly $32 \%$ of these students gave ratings of 9 or 10 regarding their educational experience, while only $18 \%$ did the same from the old curriculum.

\section{Discussion}

The present study comparatively evaluated two 


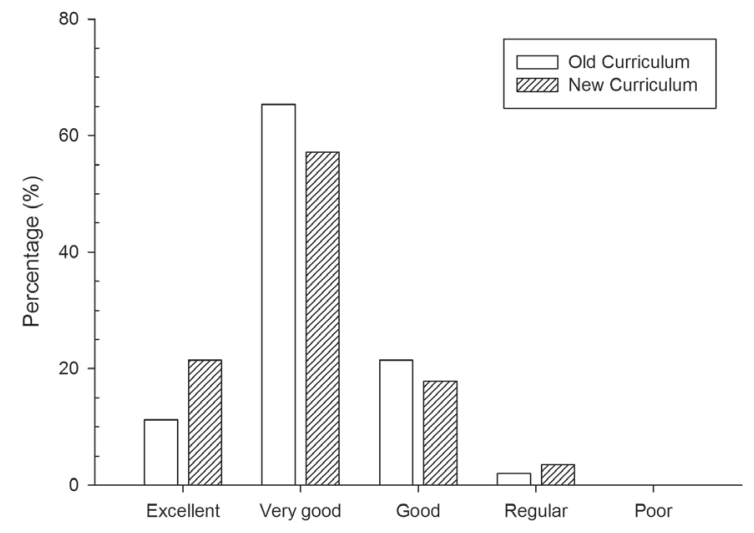

Figure 1 - Undergraduate theoretical teaching assessments as reported by the students.

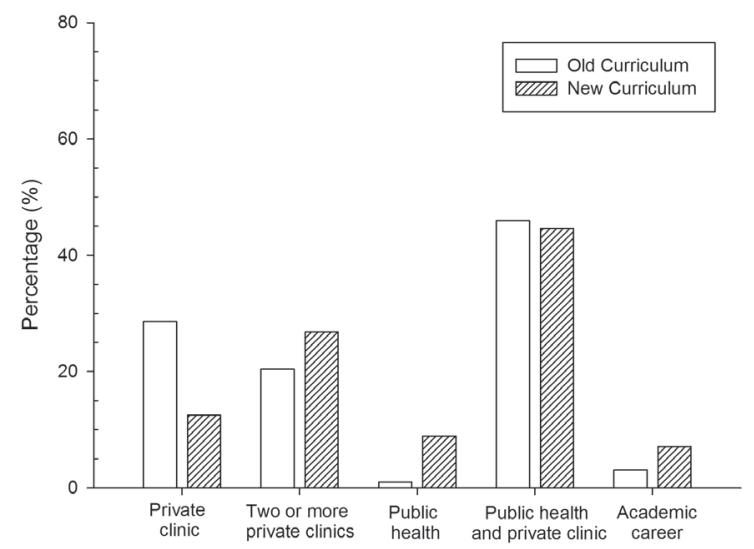

Figure 3 - Students' professional goals.

curricula in a school of dentistry in southern Brazil using a structured questionnaire, which was built for the purpose of evaluation in the school setting. It was adapted from a questionnaire that was used to compare different curricula in Norway and Brazil. ${ }^{1,7}$ Student satisfaction rates were evaluated in the present study, similar to previous studies. ${ }^{1,2,4}$

The results concerned various aspects of dental education between the two curricula. Notably, the new curriculum students used scientific articles as a study method more often than did the old curriculum students. This is a core change and possibly relates to the fact previously sustained that the new formation of the professional must be linked to technical accuracy and evidence-based applied sciences, both strongly reinforced in the new curriculum. Additionally, as more active methodologies such as seminars, clinical rounds and discussions

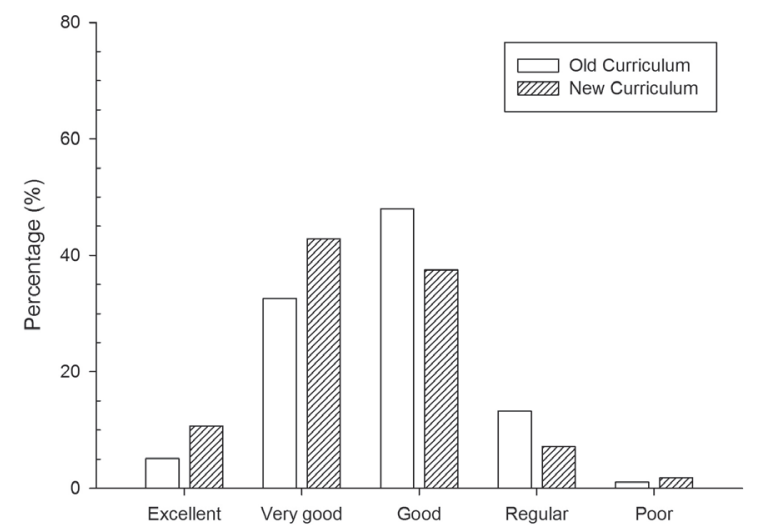

Figure 2 - Undergraduate clinical teaching assessments as reported by the students.

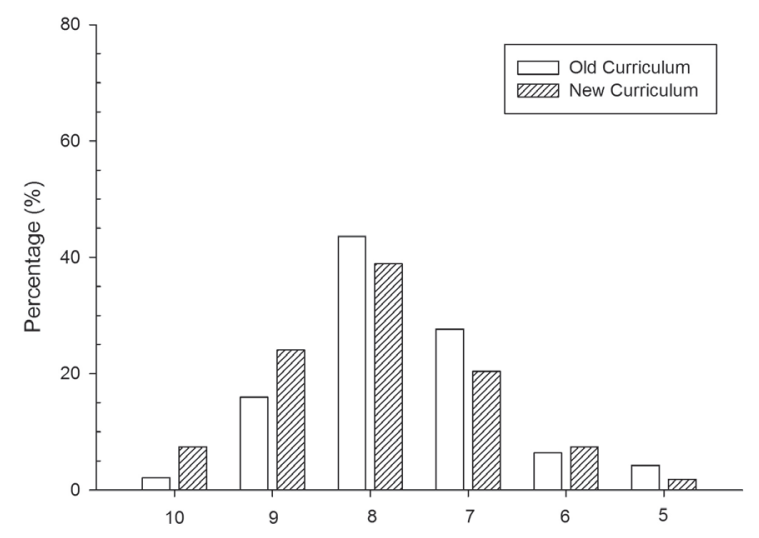

Figure 4 - Students' overall assessments (VAS from 1 to 10) of their educational experience.

are emphasized, the need for scientific support also increases. The increased use of the internet was also observed for the new curriculum graduates, reflecting these trends. A decrease in library use for studying was observed, which may reflect increased rates of virtual studying and internet access to materials that were previously only available in the library. ${ }^{8}$

High ratings for the importance of basic sciences by new curriculum graduates had been shown in previous studies. ${ }^{1,6}$ In the present study, the new curriculum students placed a higher importance on these subjects as a whole. The traditional approach to dental education, although it devoted a significant amount of time to basic science didactics, was frequently disconnected with clinical training. ${ }^{9}$ For the old curriculum students, the basic sciences were limited to the first few years of their training. In a more integrated approach, as in the new curriculum, basic 
sciences are a daily part of clinical teaching, with relevant content found in clinical rounds, seminars, and discussions, and various basic science teachers are present as consultants in the clinics. ${ }^{6,10,11}$

Regarding professional goals, in earlier times, undergraduate students in Dentistry had willingness to work in private clinics only. Considering that public dental health system was poorly developed in Brazil and hardly could provide work to all those who wanted it, old curriculum graduates showed very little interest in working only in public health settings. Such results are in disagreement with findings in a Norwegian survey. ${ }^{7}$ As a result of the evolution of the public health system in Brazil as well as programs sustaining these developments, new curriculum graduates showed more interest in working in the public health setting. The new curriculum devotes more than $20 \%$ of its content on public health practice, which allows students to experience the public health system. Such increases in communitybased experiences for dental students have been reported in previous studies. ${ }^{10,11}$

The present study also evaluated the satisfaction rates of students regarding their academic growth. This was previously studied by Farge et al., ${ }^{2}$ who compared satisfaction rates between the old curriculum and the new curriculum students at the Faculty of Dentistry in Lyon, France, in a similar manner as was done in this study. Widström et al. ${ }^{4}$ studied student satisfaction in the Nordic countries. Rösing compared dental curricula in two universities in southern Brazil with two curricula in a university in Norway. ${ }^{7}$ Two assessment methodologies were used. The first included a quality assessment of the theoretical and clinical portions of the curricula (Figures 1 and 2) while the second included an overall evaluation (Figure 4). Students in the new curriculum gave higher scores to both theoretical and clinical teaching. This may be explained by the integrated method of teaching implemented in the new curriculum. As such, students have access to continuing and integrated forms of education. ${ }^{10,11}$ The diversity of theoretical teaching, with fewer lectures and the frequent use of active teaching methodologies, might have also accounted for the higher satisfaction rates.

This study revealed differences between the two curricula regarding the graduates' abilities to perform specific clinical procedures. We can observe that students from the old curriculum alleged themselves more capable to perform amalgam restorations of any kind and three-unit prostheses. This can be explained by the growing use of resin in the dental profession, which has somewhat overshadowed the traditional use of amalgam. ${ }^{12}$ Such difference may be more of a reflection of trends in dentistry over the past decade or so instead of a reflection of curricular modifications. In the new curricular model, clinics were integrated while minimum work requirements required for graduation were alleviated. This change indicates that students from the old curriculum were more likely to perform three-unit prostheses, considering that their completion of at least one multiple-unit fixed prosthesis during their undergraduate period was a graduation requirement. Additionally, the advent of dental implants, especially in patients with a single tooth loss, may be associated with the decreased need for new curriculum students to provide fixed bridges..$^{13}$ The new curriculum graduates considered themselves to be more capable of performing periodontal surgeries, diagnosing oral lesions, treating temporomandibular joint (TMJ) disorders and participating in public health planning and execution. As was mentioned, the integration of basic science didactics and clinical training may have helped the new curriculum students gain skills in these four areas. Such significant results contradict previous studies. ${ }^{2,7}$ A lack of knowledge was perceived in specialty disciplines such as orthodontics and implant dentistry, which has already been shown in the literature. ${ }^{2}$

In order to complete this assessment, it is important to execute an evaluation along with the public health services to understand if the changes in the curriculum focus toward the formation of more generalist professionals obtained its initial purpose. It is important to note that as the old curriculum was being disrupted, the newer one was still under development and fine-tuning. Therefore, the obtained results must be analyzed with the understanding that some overlaps in opinions might exist.

Early specialization is a recurring issue not only in dental education but also in medical education. ${ }^{14}$ 
Students decide on a particular area of dental specialization and focus almost entirely in this area during their undergraduate period, therefore, they lack the broad knowledge desirable for generalist professionals. The new curriculum sought to counter the issue of early specialization using a new approach. As such, more future studies should analyze this specific issue. Another important fact that should be considered is the possibility of the Hawthorne effect, ${ }^{15}$ which can be defined as a form of reaction whereby subjects improve or modify an aspect of their behavior being experimentally measured simply in response to the fact that they are being studied. The possible presence of a novelty effect and the eventual enthusiasm with the curriculum alteration should not be ruled out as a possible explanation for the results.

As an overall understanding, the visual analogue

\section{References}

1. Rösing CK, Oppermann RV, da Silva DT, Deon P, Gjermo P. Student's appraisal of their dental education related to basic sciences learning: a comparison of four curricula in Norway and Brazil. Rev Odonto Ciênc. 2008;23(3): 234-7.

2. Farge P, Virieux J, Doury J. Student satisfaction with curriculum modifications in a French dental school. Eur J Dent Educ. 2000 Aug;4(3):112-7.

3. Greenwood F, Townsend G, Joseph V, Wetherell J. Introducing Adelaide dental students to a problem-based learning curriculum. Eur J Dent Educ. 1999 Feb;3(1):15-9.

4. Widström E, Birn H, Haugejorden O, Martinsson T. Dental student's views on their education and study circumstances in Nordic countries. Swed Dent J. 1990;14(3):123-9.

5. Brasil. Ministério da Educação. Conselho Nacional de Educação. Diretrizes Curriculares Nacionais dos Cursos de Graduação em Farmácia e Odontologia. Diário Oficial da União, Brasília (2001 dez. 07);Sec.1:25. Parecer n ${ }^{\circ}$ 1300/01, aprovado em 2001 nov. 06. Homologado. [cited 2011 May 13]. Available from: http://portal.mec.gov.br/cne/arquivos/pdf/CES1300.pdf.

6. Fiehn NE. The basic science teaching experience in the Nordic countries. Eur J Dent Educ. 1998 Aug;2(3):115-23.

7. Rösing CK, da Silva DT, Deon P, Oppermann RV, Gjermo P. Evaluation of 4 dental curricula based on student's expectations and satisfaction - report of Brazilian and Norwegian experiences. Rev ABENO. 2009 Jul-Dec;9(2):88-94.

8. De Groote SL, Barrett FA. Impact of online journals of citation patterns of dentistry, nursing and pharmacy faculty. J Med Libr Assoc. 2010 Oct;98(4):305-8. scale was used to summarize the overall evaluative process. Students under the new curriculum expressed higher satisfaction, which is considered the true endpoint in dental education. ${ }^{16}$ In this respect, one may infer that the proposed curricular changes are being well received by one of the most important parts of the academic community: the students.

\section{Conclusion}

The present study demonstrated that a new curricular approach was linked to the graduates' use of different study methods, with more emphasis on scientific articles, as well as increased importance on the basic sciences. Additionally, students reported an increased capacity to perform dental procedures, which resulted in a significantly higher rate of satisfaction than was reported with the old specialtyoriented curriculum.

9. Martínez-Alvarez C, Sanz M, Berthold P. Basic sciences education in the dental curriculum in Southern Europe. Eur J Dent Educ. 2001 May;5(2):63-6.

10. Haden NK, Hendricson WD, Kassebaum DK, Ranney RR, Weisntein G, Anderson EL, et al. Curriculum change in dental education, 2003-09. J Dent Educ. 2010 May;74(5):539-57.

11. Haden NK, Andrieu SC, Chadwick DG, Chmar JE, Cole JR, George MC, et al. The dental education environment. J Dent Educ. 2006 Dec;70(12):1265-70.

12. Lynch CD, Wilson NH. Teaching of direct posterior resin composite restorations in UK dental therapy training programmes. Br Dent J. 2010 May 8;208(9):415-21.

13. Pjetursson BE, Lang NP. Prosthetic treatment planning on the basis of scientific evidence. J Oral Rehabil. 2008 Jan;35 Suppl 1:72-9.

14. Preiss JJ, Long EC. Student attitudes toward early career commitment. Br J Med Educ. 1970 Mar;4(1):9-12.

15. McMarney R, Warner J, Iliffe S, van Haselen R, Griffin M, Fisher P. The Hawthorne Effect: a randomised, controlled trial. BMC Med Res Methodol. 2007 Jul 3;7:30. [cited 2011 May 12]. Available from: http://www.biomedcentral.com/14712288/7/30. doi:10.1186/1471-2288-7-30.

16. Divaris K, Barlow PJ, Chendea SA, Cheong WS, Dounis A, Dragan IF et al. The academic environment: the students' perspective. Eur J Dent Educ. 2008 Feb;12 Suppl 1:120-30. 